\title{
Preparation of mannitol-based ketal-linked porous organic polymers and their application for selective capture of carbon dioxide
}

Hui Li ${ }^{\text {a,b }}$, Xuesong Ding ${ }^{\mathrm{a}, *}$, Yan-Chao Zhao ${ }^{\mathrm{a}}$, and Bao-Hang Han ${ }^{\mathrm{a}, *}$

${ }^{a}$ CAS Key Laboratory of Nanosystem and Hierarchical Fabrication,

National Center for Nanoscience and Technology, Beijing 100190, China;

${ }^{\mathrm{b}}$ University of Chinese Academy of Sciences, Beijing 100049, China

Tel: 86108254 5576; Email: hanbh@,nanoctr.cn

Tel: 86108254 5708; Email: dingxs@nanoctr.cn 


\begin{abstract}
Four kinds of mannitol-based ketal-linked porous organic polymers (MKPOPs) were successfully synthesized through condensation reaction between aromatic acetyl monomers and mannitol, catalyzed by $p$-toluenesulfonic acid. The structure of resulting polymers was confirmed by Fourier transform infrared and solid-state ${ }^{13} \mathrm{C}$ nuclear magnetic resonance spectrum measurements. The porosities of MKPOPs were investigated by gas adsorption experiments and the results indicate high carbon dioxide uptake (up to $11.5 \mathrm{wt} \%$ at $273 \mathrm{~K}$ and $1.0 \mathrm{bar}$ ) for MKPOPs due to the predominant microporous and hydroxyl-rich structures. Remarkably, MKPOPs exhibit excellent selective adsorption performances for carbon dioxide over methane (9.9-14.2, IAST at $273 \mathrm{~K}$ and $1.0 \mathrm{bar})$. These studies are of significant importance for MKPOPs and their potential application in selective gas adsorption.
\end{abstract}

Keywords: porous organic polymers; mannitol; ketal-linkage; carbon dioxide capture; selective adsorption 


\section{Introduction}

In recent years, the humanity faces greatest danger from globle warming as the surge emissions of greenhouse gases $(\mathrm{GHG})$ like carbon dioxide $\left(\mathrm{CO}_{2}\right)$ or methane $\left(\mathrm{CH}_{4}\right)$. Pollution from cars and industry is one of the leading causes of GHG becoming trapped in our atmosphere. Global warming can disrupt nature's equilibrium and has lead to more droughts, floods, and other calamities. Scientists have been working hard to develop effective methods for capturing GHG. $\mathrm{CO}_{2}$ as a major GHG, not only bring damage to atmosphere, but also jeopardize the quality of natural gas that can significantly reduce the gas capacity even lead to corrosion of gas piping [1,2]. The current utilization of amine solutions to chemically capture $\mathrm{CO}_{2}$ from natural gas still has drawbacks such as energy dissipation during regeneration and the considerable hazard of volatile amine solutions. Consequently, development of new adsorbent material for selective capture of $\mathrm{CO}_{2}$ from $\mathrm{CH}_{4}$ has become a great challenge. Efforts employing porous organic polymers (POPs) have attracted considerable attentions. Porous organic materials such as metal organic frameworks (MOFs) [3-6] can exihibit efficient uptake for $\mathrm{CO}_{2}$ with large polar pore surfaces, while chemical or hydrothermal instability make them vulnerable for application. Given the aforementioned defect, POPs composed of organic building blocks and linkages are more competitive owing to their high stability and simple synthesis. Especially the organic polymers with permanent microporosity, they have wide potential applications in many fields such as gas storage [7-10], selective adsorption [11,12], organic vapor capture $[13,14]$, and 
heterocatalysis $[15,16]$. Several POPs such as hyper-cross-linked polymers (HCPs) $[17,18]$, polymers of intrinsic microporosity (PIMs) [19], and conjugated microporous polymers (CMPs) [20-22] and their performances on $\mathrm{CO}_{2}$ capture have been reported recently.

The heteroatoms (oxygen, sulphur or nitrogen) in POPs were reported to play an important role in efficient capture of polar gases and adsorption selectivity of $\mathrm{CO}_{2}$ over nitrogen or $\mathrm{CH}_{4}$ [23-26]. Based on this strategy, efficient selective sorption of $\mathrm{CO}_{2}$ over nitrogen was achieved by employing microporous organic polymers synthesized from heterocyclic aromatic monomers [27]. Sulfonate-grafted porous polymer networks exhibit significant adsorption selectivity for $\mathrm{CO}_{2}$ over nitrogen at low pressure [28]. Particularly, nitrogen-rich POPs such as BILPs [3,29], Azo-COPs [30,31], and PSNs $[32,33]$ possess high Brunauer-Emmet-Teller (BET) specific surface area along with good $\mathrm{CO}_{2} / \mathrm{N}_{2}$ or $\mathrm{CO}_{2} / \mathrm{CH}_{4}$ adsorption selectivity. Herein, we utilized mannitol to construct several ketal-linked porous organic polymers (MKPOPs). Mannitol [34-36], a polyol derived from mannose, is a cheaply available raw material with broad applications in both food and pharmaceutical industries. Combined with its polyhydroxy structure, mannitol can be promising candidate for constructing desirable POPs. MKPOPs are structurally confirmed by Fourier transform infrared (FT-IR) and solid state ${ }^{13} \mathrm{C}$ nuclear magnetic resonance (NMR) spectrum measurements. The predominant microporosities of MKPOPs are further verified by gas adsorption measurements. Owing to the high hydroxyl contents stem from polyhydric mannitol, MKPOPs exhibit 
high $\mathrm{CO}_{2}$ uptake (up to $11.5 \mathrm{wt} \%$ at $273 \mathrm{~K}$ and 1.0 bar) and considerable selectivity over $\mathrm{CH}_{4}$ (9.9-14.2, IAST at $273 \mathrm{~K}$ and 1.0 bar). These studies open up the possibilities for ketal-linked polymers in further industrial application, especially in gas separation.

\section{Experimental}

\subsection{Materials}

Ferrocene, biphenyl, mannitol, $p$-toluenesulfonic acid monohydrate (TSA), acetyl chloride, and $o$-dichlorobenzene were purchased from Beijing Chemical Reagent Corp. Ferrocene was purified by sublimation beforehand. Dichloromethane, acetone, petroleum ether, and ethyl acetate were analytical reagents and used without further purification, unless otherwise noted. 1,3,5-Triphenylbenzene and tetraphenylmethane were synthesized according to the published procedures, respectively [37,38]. Acetyl substituted aromatic monomers 1,1'-diacetylferrocene (M1), 4,4'-diacetylbiphenyl (M2), 1,3,5-tris(4-acetylphenyl)benzene (M3), and tetrakis(4-acetylphenyl)methane (M4) were synthesized respectively using the reported methods [18]. All condensation reactions were conducted using the standard Schlenk-line technique.

\subsection{Preparation of MKPOPs}

A mixture of M1 (35.1 mg, $0.13 \mathrm{mmol}$ ), mannitol (23.7 mg, $0.13 \mathrm{mmol}$ ), and TSA (500 mg, $2.63 \mathrm{mmol})$ was suspended in $o$-dichlorobenzene (4.00 mL). After ultrasonication for $0.5 \mathrm{~h}$, the mixture in a Pyrex tube was degassed by at least three freeze-pump-thaw cycles. The Pyrex tube was frozen at $77 \mathrm{~K}$ (liquid nitrogen bath) 
and evacuated to high vacuum and flame-sealed. The reaction mixture was heated at $180^{\circ} \mathrm{C}$ for $72 \mathrm{~h}$ affording a black solid. This product was collected by filtration, washed with water, ethanol, acetone, and dichloromethane and then dried in vacuo at $120^{\circ} \mathrm{C}$ for more than $12 \mathrm{~h}$ to obtain MKPOP-1 in 93\% isolated yield. Elemental analysis for $\mathrm{C}_{20} \mathrm{H}_{24} \mathrm{O}_{6} \mathrm{Fe}$ : Calculated. C, 57.71\%; H, 5.81\%. Found. C, 55.93\%; H, 2.78\%.

Similar to the preparation of MKPOP-1, M2 (31.0 mg, $0.13 \mathrm{mmol}), \mathbf{M 3}(37.5 \mathrm{mg}$, $0.087 \mathrm{mmol})$, or M4 (31.8 $\mathrm{mg}, 0.065 \mathrm{mmol})$ was used to react with mannitol (23.7 $\mathrm{mg}$, $0.13 \mathrm{mmol})$ to give MKPOP-2 $\left(95 \%\right.$ isolated yield. Elemental analysis for $\mathrm{C}_{22} \mathrm{H}_{24} \mathrm{O}_{6}$ : Calculated. C, 68.74\%; H, 6.29\%. Found. C, 70.12\%; H, 3.96\%), MKPOP-3 (93\% isolated yield. Elemental analysis for $\mathrm{C}_{39} \mathrm{H}_{39} \mathrm{O}_{9}$ : Calculated. C, 71.87\%; H, 6.03\%. Found. C, 74.55\%; H, 4.73\%), and MKPOP-4 (90\% isolated yield. Elemental analysis for $\mathrm{C}_{45} \mathrm{H}_{48} \mathrm{O}_{12}$ : Calculated. C, 69.22\%; H, 6.20\%. Found. C, 63.00\%; H, 3.67\%), respectively.

\subsection{Instrumental Characterization}

Solid-state ${ }^{13} \mathrm{C}$ cross-polarization/magic-angle-spinning (CP/MAS) NMR spectra of polymers were collected by a Bruker Avance III 400 spectrometer (Bruker, Germany). Thermogravimetric analysis (TGA) was carried out using a Pyris Diamond thermogravimetric/differential thermal analyzer (PerkinElmer Instruments Co. Ltd., USA) by heating the samples to $800{ }^{\circ} \mathrm{C}$ under an atmosphere of nitrogen (heating rate $10{ }^{\circ} \mathrm{C} \min ^{-1}$ ). FT-IR spectra of the MKPOPs were recorded on $\mathrm{KBr}$ pellets using a Spectrum One FT-IR spectrometer (PerkinElmer Instruments Co. Ltd., USA). The 
samples were prepared by pestling polymers in $\mathrm{KBr}$ and packing firmly to get transparent films, and 18 scans were signal-averaged. For scanning electron microscopy (SEM) images, samples were prepared by dropping ethanol suspensions of MKPOP-1-4 on a silicon wafer and coated with gold after drying. Images were recorded on a Hitachi S-4800 microscope (Hitachi Ltd., Japan) operating at an accelerating voltage of $6.0 \mathrm{kV}$. Transmission electron microscopy (TEM) images were collected on a Tecnai G2 F20 U-TWIN microscope (FEI, USA) at an accelerating voltage of $200 \mathrm{kV}$. Prior to TEM measurement, MKPOP-1-4 was ultrasonically dispersed in ethanol and dropped onto a copper grid coated with a carbon film, respectively. Nitrogen adsorption-desorption isotherms were recorded on an ASAP $2020 \mathrm{M}+\mathrm{C}$ accelerated surface area and porosity analyzer (Micromeritics Instrument Corporation, USA) at $77 \mathrm{~K}$. MKPOPs were degassed at $120{ }^{\circ} \mathrm{C}$ for $12 \mathrm{~h}$ under vacuum before analysis. All the gas sorption experiments were carried out twice to ensure the reproducibility. There were no noticeable distinctions in the isotherm obtained from both experiments. The nitrogen adsorption-desorption isotherms were calculated to give the pore parameters, including Brunauer-Emmet-Teller (BET) specific surface area $\left(P / P_{0}=0.01-0.10\right)$, pore size, and pore volume. The pore size distribution was calculated from the nitrogen adsorption isotherms by the non-local density functional theory (NLDFT) method using a cylindrical pore model. The pore volume was calculated from nitrogen adsorption-desorption isotherms at $P / P_{0}=0.99$. While the micropore surface area and micropore volume were calculated from nitrogen 
adsorption-desorption isotherms using the t-plot method. $\mathrm{CO}_{2}$ and $\mathrm{CH}_{4}$ adsorption isotherms were measured up to 1.0 bar at $273 \mathrm{~K}$, using a TriStar II 3020 accelerated surface area and porosity analyzer (Micromeritics Instrument Corporation, USA).

\section{Results and Discussions}

a)

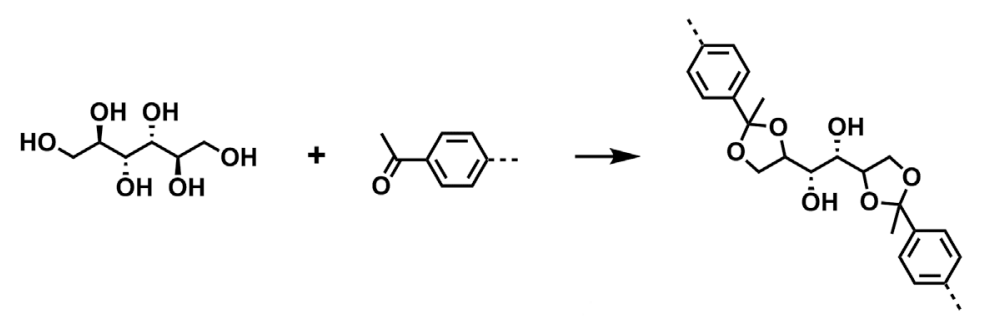

b)

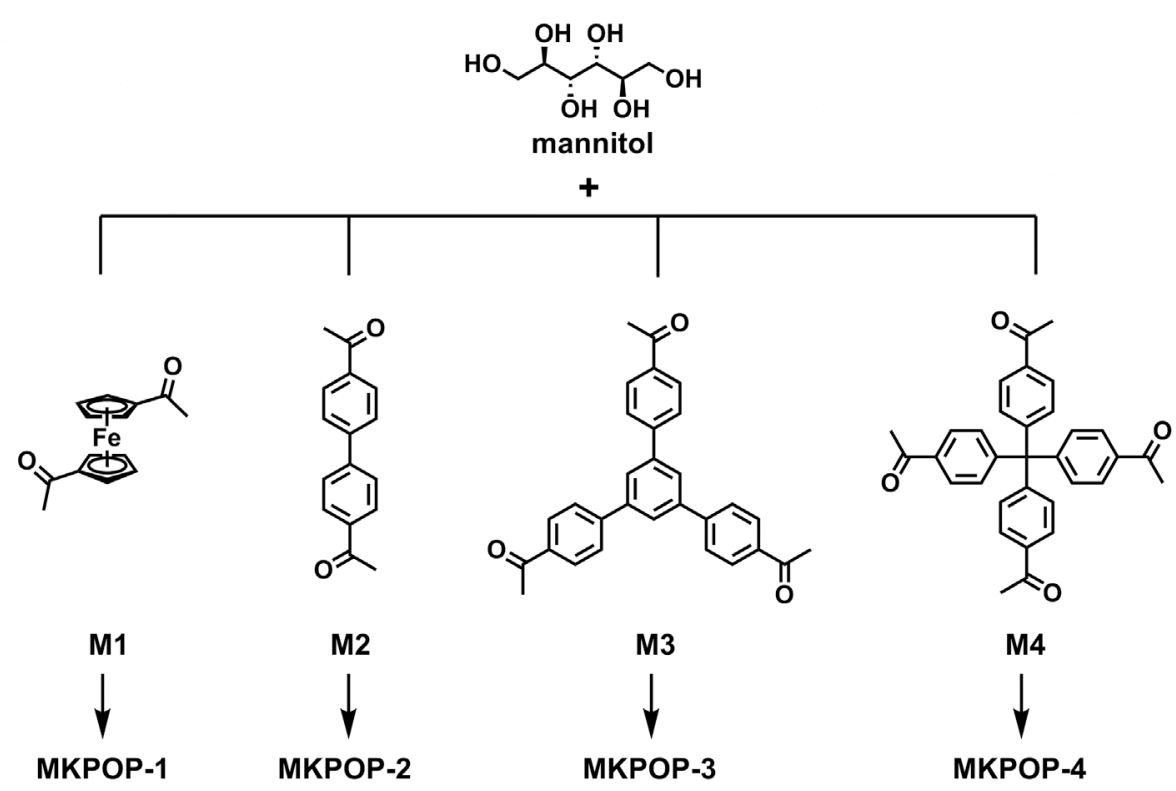

Scheme 1. (a) Reaction between mannitol and aromatic acetyl compound. (b) Synthesis routes to MKPOPs.

The ketal-linked microporous organic polymers MKPOPs were synthesized 
using the condensation reaction of acetyl containing building blocks (M1, M2, M3, or M4) with mannitol. The preparation routes to MKPOPs are presented in Scheme 1. The sealed-tube polymerization method was used instead of the conventional flask method to get materials with desired properties according to our reported results $[39,40]$. The enclosed reaction condition without oxygen is favorable for high degree of polymerization. The acetyl containing compounds were dispersed in $o$-dichlorobenzene, and TSA as a catalyst was added into the reaction mixture. After polymerization in the sealed tube at $180{ }^{\circ} \mathrm{C}$ for 3 days, four polymers (MKPOP-1-4) were obtained in quantitative yields. Normally, the ketal-linkages in MKPOPs are formed through a connection between an acetyl group and two hydroxyl groups in ortho-carbon atoms in mannitol. There are also cases that acetyl group can react with two hydroxyl groups from different mannitols (Fig. S1, Supplementary Information), thus leading to the coexistence of two kinds of structures in MKPOPs. Since it is important to design $\mathrm{CO}_{2}$ absorbents that can be mass-produced at a low cost, the synthetic method we adopted here has several advantages including cheaply available raw material and avoidance of metal catalysts. The obtained MKPOPs are stable and insoluble in most common organic solvents, such as ethanol, dichloromethane, and $\mathrm{N}, \mathrm{N}$-dimethylformamide, indicating their high degree of cross-linked structures. 


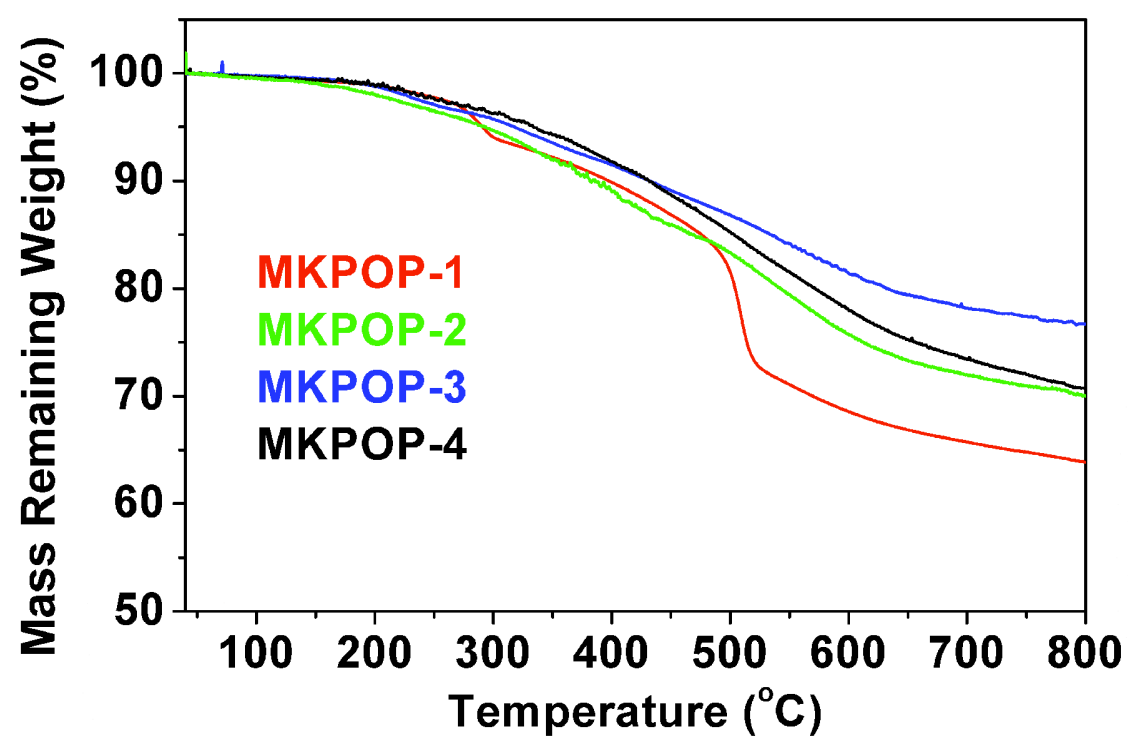

Fig. 1. TGA curves of the polymers MKPOP-1-4.

The thermal stabilities of the obtained polymers were investigated using TGA measurement from 30 to $800{ }^{\circ} \mathrm{C}$ under nitrogen atmosphere (Fig. 1). The weight loss in the initial stages $\left(<200^{\circ} \mathrm{C}\right)$ of heating is due to the evaporation of adsorbed water or trapped gas molecules in the organic porous network. No drastic weight loss occurs as the temperature increases up to $300{ }^{\circ} \mathrm{C}$ indicating the excellent thermal stability of the obtained ketal-linked networks. All the polymers show the residual mass varying from 70 to $60 \%$. SEM observations were utilized to investigate MKPOPs morphologies (Fig. S2, Supplementary Information). The SEM images reveal uniform microspheres of 2-5 $\mu \mathrm{m}$ in diameters for MKPOP-2-MKPOP-4, while no obvious morphology can be observed in case of MKPOP-1. These polymers show amorphous nature owing to the irregular nanoparticles and nanoplatelets within their structures. The high-resolution TEM images of MKPOPs further confirm their intrinsic microporous structure (Fig. S3, 
Supplementary Information).

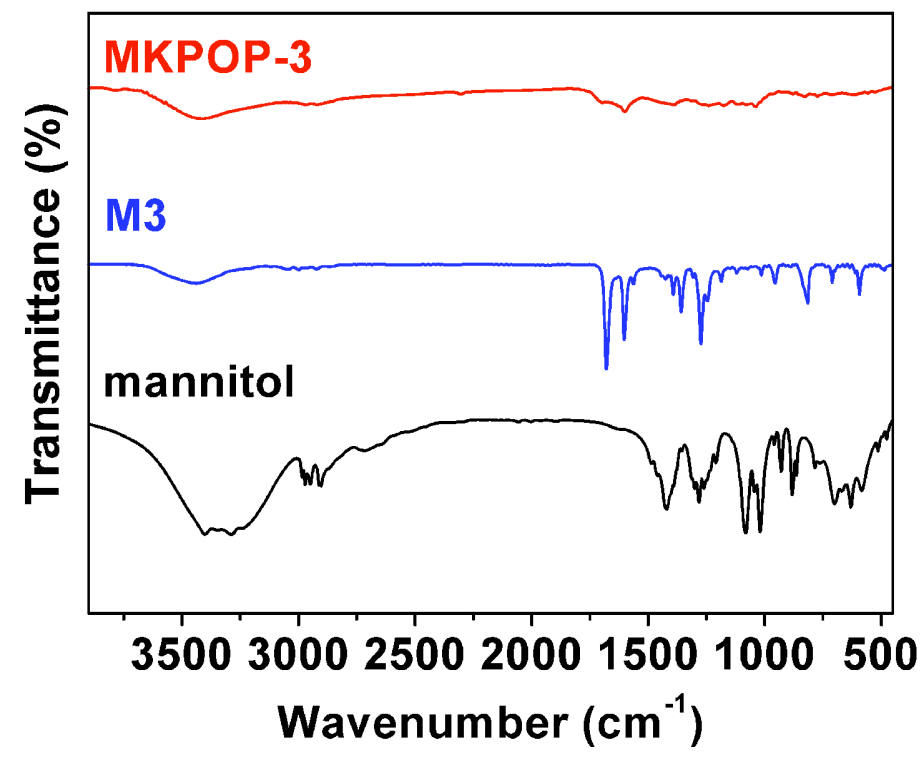

Fig. 2. FT-IR spectra of M3, mannitol, and MKPOP-3.

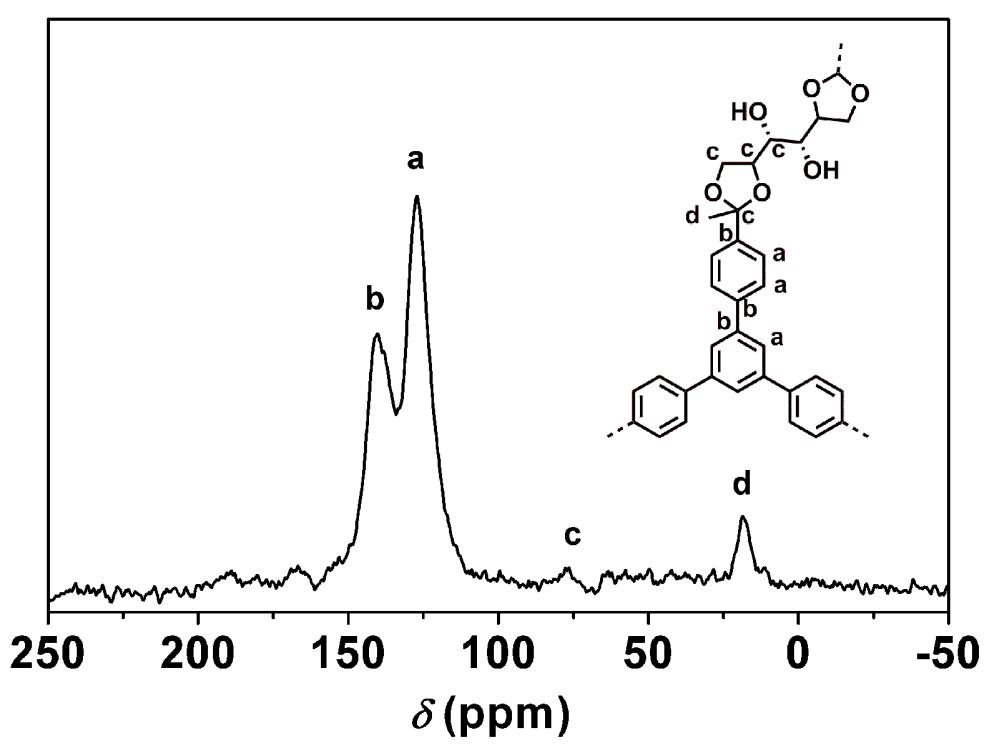

Fig. 3. Solid-state ${ }^{13} \mathrm{C}$ CP/MAS NMR spectrum of MKPOP-3. 
The formation of the ketal linkage was verified by FT-IR spectroscopic measurement (Fig. 2 and Fig. S4-S6, Supplementary Information). The consumption of the carbonyl group can be evidenced by a significant decrease in the intensity at 1690 $\mathrm{cm}^{-1}$. The broad bands that can be attributed to the stretching vibration of hydroxyl groups of mannitol around $3400 \mathrm{~cm}^{-1}$ reduce as well. These results confirm the cross-linking between acetyl monomers and mannitol. Remarkably, absorption peaks at around $1700 \mathrm{~cm}^{-1}$ assigned to the stretching vibration of the resulting ketal linkage with two oxygen atoms in the six member ring further prove the formation of desired polymers. Meanwhile, the characteristic aliphatic $\mathrm{C}-\mathrm{H}$ and $\mathrm{C}-\mathrm{O}$ absorption peaks at ca. 2900 and $1100 \mathrm{~cm}^{-1}$ are also seen for the polymers. The observed signals in the fingerprint region of the polymers indicate the reservation of aromatic structures in the corresponding monomers. Solid-state CP/MAS ${ }^{13} \mathrm{C}$ NMR spectroscopic measurement was also employed to further verify the formation of MKPOPs. The chemical shifts in the ${ }^{13} \mathrm{C}$ NMR spectra of MKPOPs, located at $78 \mathrm{ppm}$ confirm the formation of the ketal-linked polymers (Fig. 3 and Fig. S7-S8, Supplementary Information). For MKPOP-3, the signal at $19 \mathrm{ppm}$ is attributed to the methyl group originating from the acetyl monomer M3. Notably, the spectrum of MKPOP-4 exhibits a distinct resonance at $65 \mathrm{ppm}$, which can be attributed to the quaternary carbon atoms derived from the tetraphenylmethane monomer M4 (Fig. S8, Supplementary Information). The peaks for the carbon atom in the alkane backbones might overlap with that of the ketal-linkage carbon. Overall the desired structures of MKPOPs can be confirmed by the FT-IR and 
solid-state ${ }^{13} \mathrm{C}$ NMR spectra.
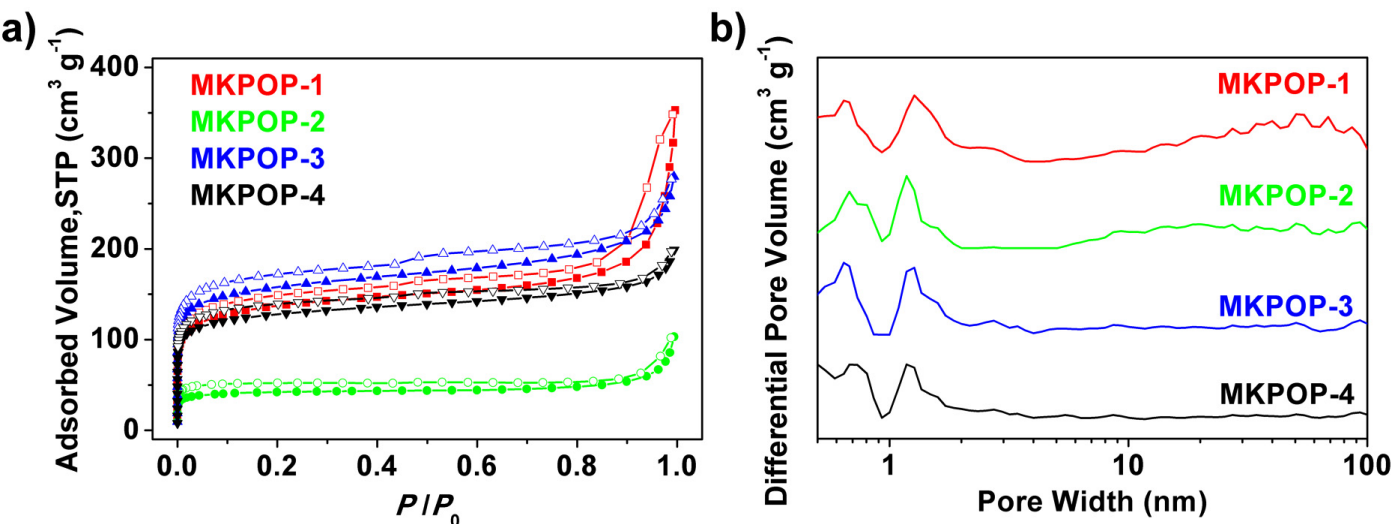

Fig. 4. (a) Nitrogen adsorption-desorption isotherms of MKPOPs measured at 77 K. (b) Pore-size distribution profiles of MKPOPs calculated by NLDFT method.

The adsorption-desorption isotherm can provide additional information on both specific surface area and pore volume of microporous networks. The porous nature of the MKPOPs was evaluated by nitrogen adsorption-desorption isotherm measurements at $77 \mathrm{~K}$ on activated samples (Fig. 4a). The polymeric networks of MKPOP-1-4 exhibit combination of type I and IV sorption isotherms [41]. A rapid nitrogen uptake at a low relative pressure $\left(P / P_{0}<0.05\right)$ indicates the predominant microporosities of MKPOPs. There is also noticeable uptake at high relative pressure $\left(P / P_{0}>0.9\right)$ especially in MKPOP-1 and MKPOP-2. These phenomena might be owing to the interparticle voids resulting from random aggregation of some nanoparticles. The sorption hysteresis existing between adsorption and desorption branches of the isotherms can be interpreted as the swelling of polymer matrix or the limited release of trapped nitrogen molecules 
from narrow pore channel [42]. The key porosity parameters obtained from the isotherms, such as the BET specific surface area, micropore surface area, micropore volume, and total pore volume are summarized in Table 1. The BET specific surface area was calculated from nitrogen adsorption isotherms (Fig. S9, Supplementary Information), and the highest BET specific surface area belongs to MKPOP-3 $\left(590 \mathrm{~m}^{2}\right.$ $\left.\mathrm{g}^{-1}\right)$. The resulting isotherms of polymers were employed to estimate the pore size distribution (PSD) profile by utilizing NLDFT model (Fig. 4b). The dominant pore size distributions of MKPOPs are in the range of $0.68-1.25 \mathrm{~nm}$. Several contiguous low peaks observed in mesopore and macropore regions especially in the PSD profiles of MKPOP-1 and MKPOP-2 are consistent with their nitrogen sorption isotherms. The pore volumes were estimated at $P / P_{0}=0.99$ and resulted in $0.16-0.55 \mathrm{~cm}^{3} \mathrm{~g}^{-1}$ for MKPOPs.

a)

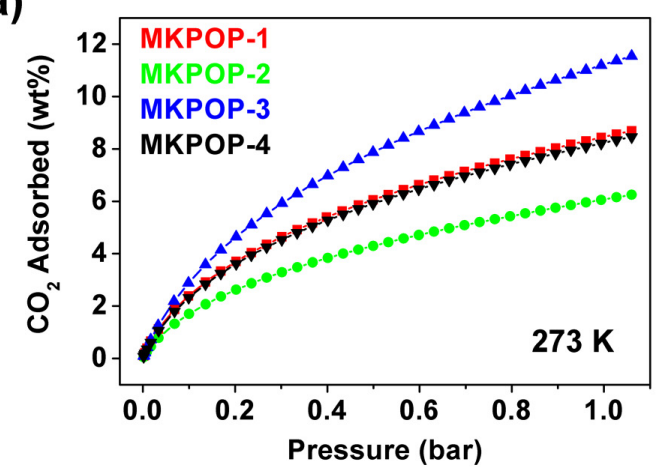

b)

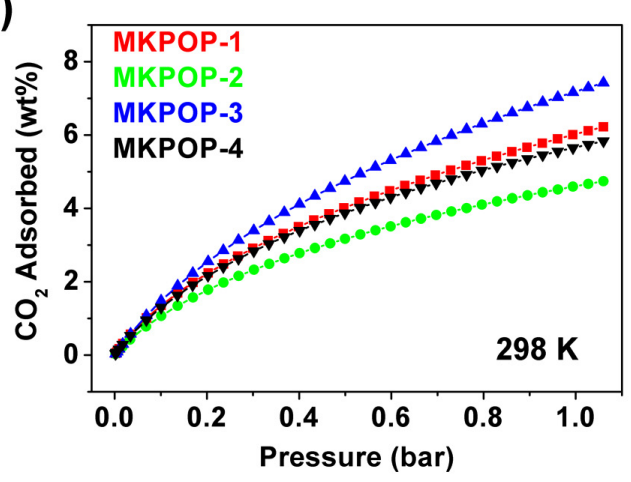

Fig. 5. $\mathrm{CO}_{2}$ adsorption isotherms of the obtained MKPOPs at (a) $273 \mathrm{~K}$ and (b) $298 \mathrm{~K}$. 
A number of literatures indicate that the $\mathrm{CO}_{2}$ capability can be enhanced significantly via the incorporation of heteroatoms (like $\mathrm{N}, \mathrm{S}$, and $\mathrm{O}$ ) in the polymer networks [23-33]. Given the considerable microporosity and abundant hydroxyl groups in MKPOPs, we further evaluate their capability for $\mathrm{CO}_{2}$ adsorption. The gas sorption measurements for $\mathrm{CO}_{2}$ were performed for all MKPOPs by volumetric methods and the results demonstrate their relatively high $\mathrm{CO}_{2}$ adsorption capability (Fig. 5 and Table 1; $6.3-11.5 \mathrm{wt} \%$ at $273 \mathrm{~K}$ and $1.0 \mathrm{bar} ; 4.7-7.4 \mathrm{wt} \%$ at $298 \mathrm{~K}$ and $1.0 \mathrm{bar}$ ). It is worth noting that the trend of the $\mathrm{CO}_{2}$ capabilities of MKPOPs is basically consistent with their BET specific surface area. One possible explanation for the result is that the considerable micropore surface area in the polymer networks might be favorable to the $\mathrm{CO}_{2}$ uptake [43]. To further investigate the binding affinity of MKPOPs for $\mathrm{CO}_{2}$, we calculated the corresponding isosteric heat $\left(Q_{\mathrm{st}}\right)$ of $\mathrm{CO}_{2}$ derived from adsorption data recorded at 273 and $298 \mathrm{~K}$ from 0 to 1.06 bar by using the Clausius-Clapeyron equation (Table 1, Fig. S10 and S11, Supplementary Information) [44]. The $Q_{\text {st }}$ value of MKPOP-3 is up to $27.1 \mathrm{~kJ} \mathrm{~mol}^{-1}$, which is higher than that of MKPOP-1 $(23.5 \mathrm{~kJ}$ $\left.\mathrm{mol}^{-1}\right)$, MKPOP-2 $\left(18.3 \mathrm{~kJ} \mathrm{~mol}^{-1}\right)$, or MKPOP-4 $\left(23.6 \mathrm{~kJ} \mathrm{~mol}^{-1}\right)$. The $Q_{\mathrm{st}}$ values practically remain constant over the whole $\mathrm{CO}_{2}$ uptake range. The largest value is comparable to that of the most reported POPs but a little less than that of the nitrogen-rich networks such as PI-1 $\left(34 \mathrm{~kJ} \mathrm{~mol}^{-1}\right)$ [45] or PECONFs $\left(26-34 \mathrm{~kJ} \mathrm{~mol}^{-1}\right)$ [46]. As shown in Table S2 (Supplementary Information), when comparing with other $\mathrm{CO}_{2}$ adsorbents, the $\mathrm{CO}_{2}$ uptakes of the MKPOPs are comparable to that of adsorbents 
with high surface area. The strong interactions play a crucial role in the good performing $\mathrm{CO}_{2}$ uptake like $-\mathrm{OH}$ in $\mathrm{POF} 1 \mathrm{~B}$, which greatly help the $\mathrm{CO}_{2}$ capturing of the materials [47]. To sum up, the obtained results reveal that high surface area, microporosity, and hydroxyl-rich structure together contribute to stronger binding affinities of polymers toward $\mathrm{CO}_{2}$.

Table 1. Porosity properties and gas uptake capacities of MKPOPs

\begin{tabular}{|c|c|c|c|c|c|c|c|}
\hline \multirow{2}{*}{ MKPOPs } & \multirow{2}{*}{$\begin{array}{c}S_{\mathrm{BET}}{ }^{a} \\
\left(\mathrm{~m}^{2} \mathrm{~g}^{-1}\right)\end{array}$} & \multirow{2}{*}{$\begin{array}{l}S_{\text {micro }}^{b} \\
\left(\mathrm{~m}^{2} \mathrm{~g}^{-1}\right)\end{array}$} & \multirow{2}{*}{$\begin{array}{c}V_{\text {micro }}{ }^{c} \\
\left(\mathrm{~cm}^{3} \mathrm{~g}^{-1}\right)\end{array}$} & \multirow{2}{*}{$\begin{array}{c}V_{\text {total }}{ }^{d} \\
\left(\mathrm{~cm}^{3} \mathrm{~g}^{-1}\right)\end{array}$} & \multicolumn{3}{|c|}{$\mathrm{CO}_{2}$ at $1.0 \mathrm{bar}^{e}$} \\
\hline & & & & & $273 \mathrm{~K}$ & $298 \mathrm{~K}$ & $Q_{\mathrm{st}}$ \\
\hline МКРОР-1 & 510 & 340 & 0.14 & 0.55 & 8.7 & 6.2 & 23.5 \\
\hline МКРОР-2 & 160 & 130 & 0.05 & 0.16 & 6.3 & 4.7 & 18.3 \\
\hline МКРОР-3 & 590 & 410 & 0.17 & 0.43 & 11.5 & 7.4 & 27.1 \\
\hline МКРОР-4 & 480 & 350 & 0.14 & 0.31 & 8.5 & 5.8 & 23.6 \\
\hline
\end{tabular}

${ }^{a}$ Specific surface area calculated from the nitrogen adsorption isotherm using the BET method in the relative pressure $\left(P / P_{0}\right)$ range from 0.01 to $0.10 ;{ }^{b}$ Micropore surface area calculated from the adsorption branch of the nitrogen adsorption-desorption isotherm using the $t$-plot method; ${ }^{c}$ Micropore volume calculated from the nitrogen adsorption isotherm using the $t$-plot method. ${ }^{d}$ Total pore volume at $P / P_{0}=0.99 ;{ }^{e} \mathrm{CO}_{2}$ uptake in $\mathrm{wt} \%$ and the isosteric enthalpies of adsorption $\left(Q_{\mathrm{st}}\right)$ in $\mathrm{kJ} \mathrm{mol}^{-1}$. 
Table 2. Corresponding data of $\mathrm{CO}_{2}$ separation for MKPOPs.

\begin{tabular}{lccccc}
\hline & \multicolumn{2}{c}{$\mathrm{CO}_{2} / \mathrm{CH}_{4}$ selectivity } & $\mathrm{CO}_{2} / \mathrm{N}_{2}$ selectivity \\
\cline { 2 - 6 } MKPOPs & initial & & & initial & \\
& & IAST $^{b}$ & IAST $^{c}$ & & IAST $^{d}$ \\
& slope $^{a}$ & & & slope $^{a}$ & \\
\hline MKPOP-1 & 19.4 & 12.8 & 4.4 & 75.2 & 21.9 \\
MKPOP-2 & 13.5 & 9.9 & 3.6 & 60.0 & 17.2 \\
MKPOP-3 & 16.6 & 10.8 & 4.3 & 104.3 & 29.8 \\
MKPOP-4 & 21.8 & 14.2 & 4.7 & 105.2 & 33.8 \\
\hline
\end{tabular}

${ }^{a}$ Selectivity $\left(\mathrm{mol} \mathrm{mol}^{-1}\right.$ ) was calculated by initial slope method at $273 \mathrm{~K} .{ }^{b}$ Selectivity (mol mol ${ }^{-1}, 1.0$ bar) was calculated by IAST method at mole ratio of $5 / 95$ for $\mathrm{CO}_{2} / \mathrm{CH}_{4}$ (natural gas model) at $273 \mathrm{~K} .{ }^{c}$ Selectivity $\left(\mathrm{mol} \mathrm{mol}^{-1}, 1.0 \mathrm{bar}\right.$ ) was calculated by IAST method at mole ratio of 50/50 for $\mathrm{CO}_{2} / \mathrm{CH}_{4}$ (shale gas model) at $273 \mathrm{~K}$. ${ }^{d}$ Selectivity (mol mol ${ }^{-1}, 1.0$ bar) was calculated by IAST method at mole ratio of $15 / 85$ for $\mathrm{CO}_{2} / \mathrm{N}_{2}$ at $273 \mathrm{~K}$.

$\mathrm{CH}_{4} / \mathrm{CO}_{2}$ mixed gas are widely found in natural gas, biogenic gas, and oil field gas, masses of $\mathrm{CO}_{2}$ in the mixture can directly influence the combustion effect or the quality of the gas product. Based on the promising microporous properties resulted from MKPOPs, we decide to determine their $\mathrm{CO}_{2}$ uptake selectivity over $\mathrm{CH}_{4}$ to assess the potential application in gas separation. To investigate the $\mathrm{CO}_{2} / \mathrm{CH}_{4}$ selectivity, single component adsorption isotherms of $\mathrm{CO}_{2}$ and $\mathrm{CH}_{4}$ were collected at $273 \mathrm{~K}$ and $0-1.06$ 
bar. $\mathrm{CO}_{2} / \mathrm{CH}_{4}$ selectivity was first calculated by use of the initial slope ratios estimated from Henry's law constants that derived from single-component adsorption isotherms in the low pressure range (Table 2 and Fig. S12, Supplementary Information). The calculated $\mathrm{CO}_{2} / \mathrm{CH}_{4}$ selectivity of MKPOP-4 is 22 at $273 \mathrm{~K}$. Notably, the $\mathrm{CO}_{2} / \mathrm{CH}_{4}$ selectivities of MKPOP-1-3 are found to be in the range of 13-19, indicating possibilities of MKPOPs for further use in $\mathrm{CO}_{2}$ removal from pre-combustion gases.

a)

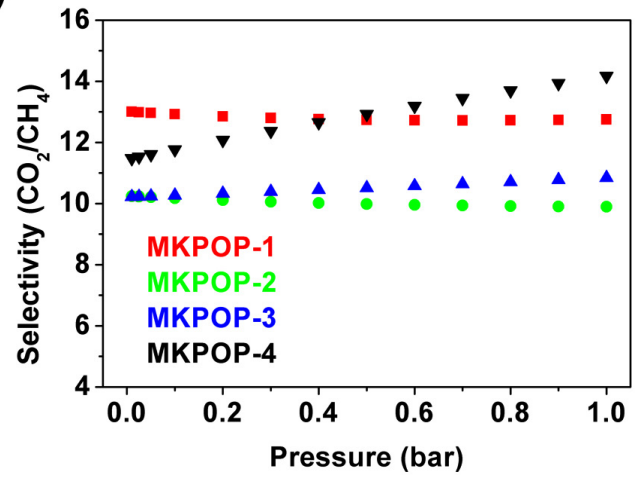

b)

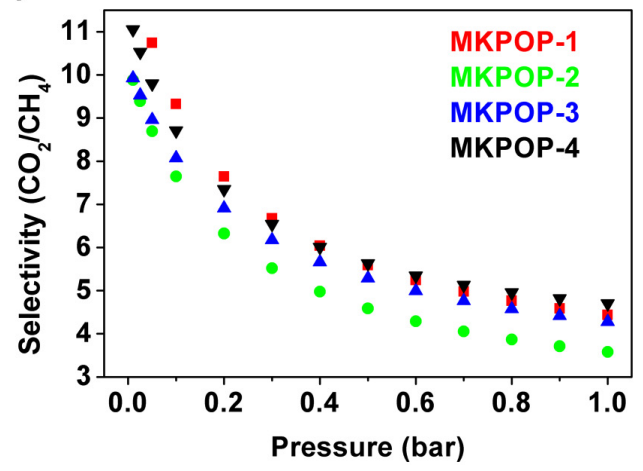

Fig. 6. IAST selectivity of MKPOPs for (a) $0.05 / 0.95 \mathrm{CO}_{2} / \mathrm{CH}_{4}$ mixture (natural gas model) (b) $0.50 / 0.50 \mathrm{CO}_{2} / \mathrm{CH}_{4}$ mixture (shale gas model) calculated at $273 \mathrm{~K}$.

The ideal adsorbed solution theory (IAST) [48] is a generally applied method to evaluate the adsorption behavior of binary gas mixture in porous organic materials [49-52]. The $\mathrm{CO}_{2}$ and $\mathrm{CH}_{4}$ isotherms of MKPOPs collected at $273 \mathrm{~K}$ are well fitted by using the dual-site Langmuir model and the single-site Langmuir model, respectively (black lines in Fig. S14, Supplementary Information). The initial significant rise in uptake of $\mathrm{CO}_{2}$ compared with $\mathrm{CH}_{4}$ might be owing to the interactions of $\mathrm{CO}_{2}$ with 
accessible hydroxyl sites of mannitol. The resulting IAST data for MKPOPs are listed in Table 2. By specifying the natural gas composition as $\mathrm{CO}_{2} / \mathrm{CH}_{4}=0.05 / 0.95$, the selectivities of $\mathrm{CO}_{2} / \mathrm{CH}_{4}$ for MKPOPs are shown in Fig. 6a. Remarkably, MKPOP-4 exhibits the highest $\mathrm{CO}_{2}$ over $\mathrm{CH}_{4}$ selectivity (14.2) among all MKPOPs at $273 \mathrm{~K}$ and 1.0 bar. When we simulate the shale gas composition as $\mathrm{CO}_{2} / \mathrm{CH}_{4}=0.5 / 0.5$, the IAST selectivities for MKPOPs were calculated varies from 3.6 to 4.7 at $273 \mathrm{~K}$ and 1.0 bar (Fig. 6b). It should be noted that the $\mathrm{CO}_{2} / \mathrm{CH}_{4}$ selectivities of MKPOPs (9.9-14.2) are comparable even superior to those of the reported POPs with higher BET specific surface area and $\mathrm{CO}_{2}$ capability, such as PANs (7 and 10, $273 \mathrm{~K}, 1.0$ bar) [33] and APOPs $(5.3-6.7,273 \mathrm{~K}, 1.0$ bar) [52]. To sum up, the IAST data and the calculated initial slopes ratios give consistent results, i.e. MKPOPs exhibit satisfactory separation performance for $\mathrm{CO}_{2}$ over $\mathrm{CH}_{4}$ at $273 \mathrm{~K}$ (Table 2).

To further evaluate the selectivity of $\mathrm{CO}_{2}$ over $\mathrm{N}_{2}$ for MKPOPs under simulated flue-gas conditions $\left(15 \% \mathrm{CO}_{2}, 85 \% \mathrm{~N}_{2}\right)$, IAST model was used to calculate the molar loadings of the polymers in $\mathrm{CO}_{2}$ separation from gas mixtures. The experimental $\mathrm{N}_{2}$ isotherms collected at $273 \mathrm{~K}$ for MKPOPs were fitted to the single-site Langmuir model (black lines in Fig. S15, Supplementary Information). The calculated IAST for MKPOPs is shown in Table 2 and Fig. S16 (Supplementary Information). At $273 \mathrm{~K}$ and 1.0 bar, MKPOP-4 exhibits the highest $\mathrm{CO}_{2}$ over $\mathrm{N}_{2}$ selectivity (33.8) among all four polymers. The $\mathrm{CO}_{2} / \mathrm{N}_{2}$ selectivity calculated by the initial slope ratios (Fig. S13, Supplementary Information) is shown in Table 2, and the highest value of $\mathrm{CO}_{2} / \mathrm{N}_{2}$ 
selectivity for MKPOPs is 105 at $273 \mathrm{~K}$.

\section{Conclusions}

In summary, we have prepared four new MKPOPs by classic acid catalyzed condensation between aromatic acetyl monomers and mannitol. This synthesis method is economical and environmentally friendly compared to traditional metal-catalyzed polymerization. The solid-state ${ }^{13} \mathrm{C}$ NMR spectroscopy and FT-IR confirm the anticipated structures of the obtained polymers. MKPOPs exhibit high $\mathrm{CO}_{2}$ uptake (up to $11.5 \mathrm{wt} \%$ at $273 \mathrm{~K}$ and $1.0 \mathrm{bar}$ ) owing to their predominant microporous and hydroxyl-rich structures. Furthermore, MKPOPs show considerable $\mathrm{CO}_{2}$ over $\mathrm{CH}_{4}$ selectivity (9.9-14.2, IAST at $273 \mathrm{~K}$ and $1.0 \mathrm{bar}$ ) in a specified natural gas composition $\left(\mathrm{CO}_{2} / \mathrm{CH}_{4}=0.05 / 0.95\right)$. These investigations render the ketal-linked microporous polymers promising candidates for selective gas adsorption.

\section{Acknowledgements}

We thank the financial support of the National Science Foundation of China (Grants no. 21304022 and 21374024). 


\section{References}

[1] Mastalerz M, Schneider MW, Oppel IM, Presly OA. Angew Chem Int Ed 2011;50:1046-51.

[2] D’Alessandro DM, Smit B, Long JR. Angew Chem Int Ed 2010;49:6058-82.

[3] Thomas A. Angew Chem Int Ed 2010;49:8328-44.

[4] Sumida K, Rogow DL, Mason JA, McDonald TM, Bloch ED, Herm ZR, Bae T, Long JR. Chem Rev 2012;112:724-81.

[5] Furukawa H, Ko N, Go YB, Aratani N, Choi SB, Choi E, Yazaydin AO, Snurr RQ, O’Keeffe M, Kim J, Yaghi OM. Science 2010;329:424-8.

[6] Banerjee R, Phan A, Wang B, Knobler C, Furukawa H, O’Keeffe M, Yaghi OM. Science 2008;319:939-45.

[7] Furukawa H, Yaghi OM. J Am Chem Soc 2009;131:8875-83.

[8] Rabbani MG, El-Kaderi HM. Chem Mater 2011;23:1650-3.

[9] Chen Q, Luo M, Hammershøj P, Zhou D, Han Y, Laursen BW, Yan CG, Han BH. J Am Chem Soc 2012;134:6084-7.

[10] Zhao YC, Cheng QY, Zhou D, Wang T, Han BH. J Mater Chem 2012;22:11509-14.

[11] Jin YH, Voss BA, Jin A, Long H, Noble RD, Zhang W. J Am Chem Soc $2011 ; 133: 6650-8$.

[12] Rabbani MG, Reich TE, Kassab RM, Jackson KT, El-Kaderi HM. Chem Commun 2012;48:1141-3.

[13] Zhao YF, Yao KX, Teng BY, Zhang T, Han Y. Energy Environ Sci 
$2013 ; 6: 3684-92$.

[14] Chen Q, Liu DP, Zhu JH, Han BH. Macromolecules 2014;47:5926-31.

[15] Ding SY, Gao J, Wang Q, Zhang Y, Song WG, Su CY, Wang W. J Am Chem Soc $2011 ; 133: 19816-22$.

[16] Zhang K, Kopetzki D, Seeberger PH, Antonietti M, Vilela F. Angew Chem Int Ed $2013 ; 52: 1432-6$.

[17] Wood CD, Tan B, Trewin A, Niu H, Bradshaw D, Rosseinsky MJ, Khimyak YZ, Campbell NL, Kirk R, Stöckel E, Cooper AI. Chem Mater 2007;19:2034-48.

[18] Rose M, Bohlmann W, Sabo M, Kaskel S. Chem Commun 2008;44:2462-4.

[19] McKeown NB, Budd PM. Chem Soc Rev 2006;35:675-8.

[20] Weber J, Thomas A. J Am Chem Soc 2008;130:6334-5.

[21] Jiang JX, Su F, Trewin A, Wood CD, Niu H, Jones JTA, Khimyak YZ, Cooper AI. J Am Chem Soc 2008;130:7710-20.

[22] Chen L, Yang Y, Jiang DL. J Am Chem Soc 2010;132:9138-43.

[23] Jin Y, Voss BA, McCaffrey R, Baggett CT, Noble RD, Zhang, W. Chem Sci $2012 ; 3: 874-7$.

[24] Yu H, Tian M, Shen C, Wang Z. Polym Chem 2013;4:961-8.

[25] Katsoulidis AP, Dyar SM, Carmieli R, Malliakas CD, Wasielewski MR, Kanatzidis MG. J Mater Chem A 2013;1:10465-73.

[26] Ding X, Li H, Zhao YC, Han BH. Polym Chem 2015;6:5305-12.

[27] Luo Y, Li B, Wang W, Wu K, Tan B. Adv Mater 2012;24:5703-7. 
[28] Lu W, Yuan D, Sculle J, Zhao D, Krishna R, Zhou HC. J Am Chem Soc 2011;133:18126-9.

[29] Sekizkardes AK, İslamoğlu T, Kahveci Z, El-Kaderi HM. J Mater Chem A 2014;2:12492-500.

[30] Patel HA, Je SH, Park J, Chen DP, Jung Y, Yavuz CT, Coskun A. Nat Commun $2013 ; 4: 1357$.

[31] Patel HA, Je SH, Park J, Jung Y, Coskun A, Yavuz CT. Chem -Eur J 2014;20:772-80.

[32] Li G, Zhang B, Yan J, Wang Z. Chem. Commun. 2014;50:1897-9.

[33] Li G, Zhang B, Yan J, Wang Z. Macromolecules 2014;47:6664-70.

[34] Cho BT, Chun YS. Tetrahedron-Asymmetr 1998;9:1489-92.

[35] Xing A, Pang Z, Li H, Wang L. Tetrahedron 2014;70:8822-8.

[36] Rockwell K. J. Exot. Pet Med 2015;24:120-2.

[37] Elmorsy SS, Pelter A, Smith K. Tetrahedron Lett 1991;32:4175-6.

[38] Tanemura K, Suzuki T, Nishida Y, Horaguchi T. Tetrahedron Lett 2008;49:6419-22.

[39] Han Y, Zhang LM, Zhao YC, Wang T, Han BH. ACS Appl Mater Interfaces 2013;5:4166-72.

[40] Zhao YC, Zhang LM, Wang T, Han BH. Polym Chem 2014;5:614-21.

[41] Sing KSW, Everett DH, Haul RAW, Moscou L, Pierotti RA, Rouquérol J, Siemieniewska T. Pure App Chem 1985;57:603-19. 
[42] Weber J, Schmidt J, Thomas A, Böhlmann W. Langmuir 2010;26:15650-6.

[43] Farha OK, Bae YS, Hauser BG, Spokoyny AM, Snurr RQ, Mirkin CA, Hupp JT. Chem Commun 2010;46:1056-8.

[44] Dunne JA, Rao M, Sircar S, Gorte RJ, Myers AL. Langmuir 1996;12:5896-904.

[45] Laybourn A, Dawson R, Clowes R, Iggo JA, Cooper AI, Khimyak YZ, Adams DJ. Polym Chem 2012;3:533-37.

[46] Mohanty P, Kull LD, Landskron K. Nat Commun 2011;2:402.

[47] Katsoulidis AP, Kanatzidis MG. Chem Mater 2011;23:1818-24.

[48] Myers A, Prausnitz JM. AlChE J 1965;11:121-7.

[49] Farha OK, Spokoyny AM, Hauser BG, Bae YS, Brown SE, Snurr RQ, Mirkin CA, Hupp JT. Chem Mater 2009;21:3033-5.

[50] Xiang Z, Zhou X, Zhou C, Zhong S, He X, Qin C, Cao D. J Mater Chem 2012;22:22663-9.

[51] Reich TE, Behera S, Jackson KT, Jena P, El-Kaderi HM. J Mater Chem 2012;22:13524-8.

[52] Song WC, Xu XK, Chen Q, Zhuang ZZ, Bu XH. Polym Chem 2013;4:4690-6. 


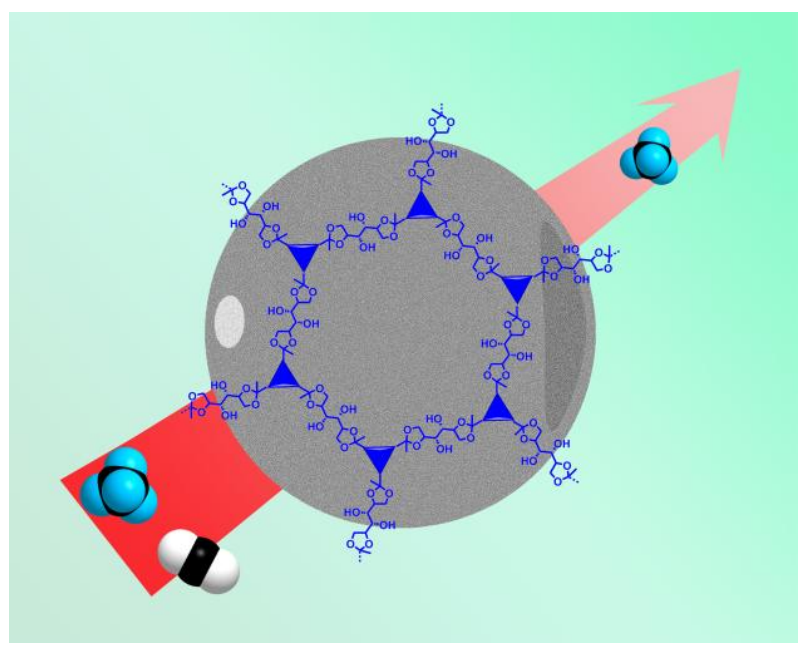

\section{Graphic TOC}

